This item was submitted to Loughborough's Research Repository by the author.

Items in Figshare are protected by copyright, with all rights reserved, unless otherwise indicated.

\title{
Removal of heat-formed coating from a titanium alloy using high pressure waterjet: Influence of machining parameters on surface texture and residual stress
}

\section{PLEASE CITE THE PUBLISHED VERSION}

http://dx.doi.org/10.1016/j.jmatprotec.2015.03.053

\section{PUBLISHER}

(C) Elsevier

\section{VERSION}

AM (Accepted Manuscript)

\section{PUBLISHER STATEMENT}

This work is made available according to the conditions of the Creative Commons Attribution-NonCommercialNoDerivatives 4.0 International (CC BY-NC-ND 4.0) licence. Full details of this licence are available at: https://creativecommons.org/licenses/by-nc-nd/4.0/

\section{LICENCE}

CC BY-NC-ND 4.0

\section{REPOSITORY RECORD}

Huang, L., Peter Kinnell, and P.H. Shipway. 2019. "Removal of Heat-formed Coating from a Titanium Alloy Using High Pressure Waterjet: Influence of Machining Parameters on Surface Texture and Residual Stress". figshare. https://hdl.handle.net/2134/21438. 


\title{
Removal of Heat-formed Coating from a Titanium Alloy using High Pressure Waterjet: Influence of Machining Parameters on Surface Texture and Residual Stress
}

\author{
L. Huang ${ }^{\text {a, * }}$, P. Kinnell ${ }^{\text {a }}$ P.H. Shipway ${ }^{b}$
}

\begin{abstract}
${ }^{a}$ Manufacturing Research Division, Faculty of Engineering, The University of Nottingham, University Park, Nottingham, NG7 2RD, United Kingdom

b Materials, Mechanics and Structures Research Division, Faculty of Engineering, The University of Nottingham, University Park, Nottingham, NG7 2RD, United Kingdom
\end{abstract}

\section{Abstract}

Titanium alloys are widely used in aerospace and medical industries owing to high strength to weight ratio and outstanding corrosion resistance. A problem for titanium or titanium alloys is the existence of a hard, brittle and oxygen-enriched layer on the surface (so called alpha case) which is usually formed during hot forming processes or after long-term service at elevated temperatures in an open-air environment. With the development of waterjet system, high pressure waterjet has shown its capability for the removal of such hard and difficult-tomachine coatings. Waterjet machining is usually associated with a surface roughening effect due to the repetitive impacts of droplets. Surface roughening is unwanted for most of aerospace applications as rough surface is detrimental to the fatigue behavior of components, but is beneficial for medical application where fixation is required (e.g. metal orthopedic implants). An additional benefit of waterjet material removal is that the repetitive droplet impacts may introduce compressive residual stress to the machined surface and subsurface layers. In this study, Ti-6Al-4V with alpha case layer was subjected to plain waterjet over a range of parametric conditions. The completeness of alpha case removal was characterized by the depth of removal. The textured surfaces were quantified in terms of average surface roughness $(R a)$ and apparent volume for interdigitation $\left(V_{i}\right)$. The magnitude of residual stress of PWJ-machined surfaces was measured using X-ray diffraction (XRD). ANOVA analysis was also conducted to identify the relative significance of machining parameters to the process outputs. It was found that an increase in removal depth results in an increase in the surface roughness as well as the interdigitation volume regardless of machining conditions. A compressive residual stress (-563 $\mathrm{MPa} \sim-13 \mathrm{MPa}$ ) was found within all PWJ-machined surfaces. It was concluded that a maximum compressive residual stress simultaneous to a

* Corresponding author. Tel: +86 (0)21-58448969; fax: +86 (0)21-58448969.

E-mail address: h_lei2000@hotmail.com (L. Huang). 
minimum material loss of the Ti-6Al-4V substrate can be obtained by controlling the exposure time (or traverse rate) when the other machining parameters are fixed.

Keywords: Plain waterjet, alpha case removal, Ti-6Al-4V, residual stress

* Corresponding author. Tel: +86 (0)21-58448969; fax: +86 (0)21-58448969.

E-mail address: h_lei2000@hotmail.com (L. Huang). 


\section{Introduction}

Ultra-high pressure plain waterjet (PWJ) technology has been considered as a promising substitute metal removing method over other techniques such as chemical etching or abrasive-evolved processes due to its distinct features which are beneficial to the ultimate performance of the processed components such as no heat-effected zone, no abrasive contamination, environmental friendly and industrial affordable cost, etc.. With significant improvement on pump technology in recent years, the removal of extremely hard protective coatings or heat-formed coatings (e.g. heat-formed titanium alpha case) using PWJ has become possible. A potential extra benefit of removing alpha case using PWJ process is that PWJ may be capable of introducing compressive residual stress to the treated surface simultaneous to material removal.

As Chillman et al. (2010) described, alpha case is a brittle, oxygen-enriched and all alpha surface layer on the titanium alloys, which is usually formed during hot forming processes such as superplastic forming (SPF) or after long-term service at elevated temperatures in an open-air environment. Frangini et al. (1994) and Patankar and Tan (2001) both stated that the alpha case layer is detrimental because of the brittle nature of oxygen enriched alpha phased structure which renders itself crack initiation and propagation. A preliminary study in removing alpha case by a high pressure water-air jet has been conducted by Chillman et al. (2010). The resulting surface roughness and completeness of alpha case removal were characterized. It was concluded that the depth of removal can be controlled by the energy per unit area transferred to the workpiece with minimal effect on the resulting surface topography. It was also speculated that the repetitive impacts of droplets serve to introduce compressive residual stress in shallow subsurface layers of the work piece. However, neither a parametric study investigating the effects of machining parameters on alpha case removal nor the residual stress study was involved in their work.

Residual stress is a stress state present in material in the absence of any external forces, which is a self-equilibrating stress that has a zero resultant force. It has been widely recognized that compressive residual stress on various components to be cyclically loaded is beneficial as it prevents stress corrosion cracking and fatigue fracturing. This is due to that, for a fatigue crack to propagate during the loading cycle, the region at the crack tip must be in a state of tension. Vosough et al. (2005) claimed that when a compressive residual stress state has been superimposed over the stress state resulting from the service loading, it is possible 
that most of or the entire load spectrum will remain in the compression region. The methods enrolled for the formation of compressive residual stresses include shot peening, abrasive finishing, cold rolling and recently-emerged laser peening and waterjet peening.

Surface residual stresses resulting from waterjetting processes have been reported by a few researchers. Arola and Ramulu (1997) studied the residual stresses on AWJ-cut kerfs of six different metals including Ti-6Al-4V. A significant bi-axial compressive residual stress was observed in the plane of the machined surface for all materials and cutting conditions; and a positive stress gradient was found to exist below the machined surface of Ti-6Al-4V. Tonshoff et al. (1997) carried out study in PWJ peening of case hardened steel and measured the residual stresses of PWJ-peened surfaces processed with various peening durations. It was demonstrated that with increasing peening duration the magnitude of compressive stress increases up to a maximum level and then decreases distinctly with even longer peening durations. Similar results were observed by Soyama et al. (2004) who examined the compressive residual stress into Ti-6Al-4V by cavitation peening. XRD residual stress measurement in their study suggested that with the increase of exposure time per unit length the compressive residual stress induced firstly has a sharp increase until it reaches the maximum. It is interesting that with further increase of the exposure time the magnitude of compressive residual stress decreases slightly. Arola et al. (2001) investigated the effects of treatment parameters on residual stresses resulting from PWJ and AWJ peening of Ti-6Al-4V using XRD method. It showed that in AWJ peening of Ti-6Al-4V the magnitude of compressive residual stress in the material increased with a decrease in jet pressure and abrasive size which is in accordance with Arola and McCain (2000), while in PWJ peening of the same material the compressive residual stress increased with an increase in jet pressure. They explained this as that in the former case with the increase of jet pressure and abrasive size, the energy of jet increased and was available for hydrodynamic erosion so that removal of surface layers contributed to the near-surface stress relief and consequently a reduction in compressive residual stress; in the latter case the absence of material removal resulted in an increase in the near-surface deformation with increasing pressure.

Most of the existing work in the study of residual stress in reference to waterjetting processes highlights on the application of waterjet peening. A special characteristic of peening process which was defined by Tonshoff et al. (1997) is that there are only negligible modifications on the peened surface in terms of surface roughness and topography. Waterjet removal process, however, is associated with significant modifications on the treated surface; and the initially 
deformed zone may be partly or totally removed by the subsequent jet impact. Nevertheless, it is confident to believe that regardless of the magnitude of material removal the PWJ-treated surface will retain a certain value of compressive stress due to that the continuous droplet impacts will successively introduce material deformation although the initially deformed zone may be removed by subsequent impacts. Thus, it is worth studying the potential compressive residual stress introduced on PWJ-removed surfaces which has not been reported elsewhere.

Waterjet surface treatment may result in a decrease in surface roughness of the treated surface due to the uneven droplets impacts over the impinged area. The contribution of surface roughness to crack initiation during cyclic loading has been a long-standing concern. Meguid (1989) demonstrated that small crack-like defects and rough surface formed during the shot peening process have shown to be detrimental to fatigue crack initiation for aluminum. However, the compressive residual stress induced during waterjet impingement may be sufficient to retard crack initiation from large surface irregularities. Arola et al. (2006) reported that an increase in residual stress is always associated with a corresponding increase in surface roughness $\left(R_{a}\right)$ for AWJ-peened AISI 304. Fatigue test revealed that crack initiation in the AWJ-peened specimen even with large surface roughness (up to $14 \mu \mathrm{m}$ in $\mathrm{Ra}$ ) occurred approximately 150-200 $\mu \mathrm{m}$ below the surface. In contrast, in the untreated fatigue specimen, failure initiated from the surface. This proved that the residual stress suppressed crack initiation from the surface despite the large roughness resulting from peening.

This paper reports on the development of a novel process using ultra-high pressure plain waterjet for the removal of titanium alpha case with an investigation of the effects of key machining parameters on the outcomes of alpha case removal process, and for the first time measures the surface residual stresses on PWJ-removed surfaces. Depth of removal-DOR, surface roughness parameter- $R a$ and interdigitation volume- $V_{i}$ are used to evaluate the completeness of alpha case removal and surface topography; and X-ray diffraction (XRD) method is applied to measure the surface residual stress. The influence of waterjet parameters on removal depth, surface topography as well as surface residual stresses are investigated by an analysis of variance (ANOVA). 


\section{Materials and experimental procedure}

\subsection{Materials}

The material subjected to PWJ impingement in this study was alpha case contaminated Ti6Al-4V (EN3354). The material was in sheet form with a dimension of $75 \mathrm{~mm} \times 75 \mathrm{~mm} \times 1$ $\mathrm{mm}$. The alpha case layer was formed after heating at $890^{\circ} \mathrm{C}$ for 1 hour. The thickness of the alpha case layer on both sides of the sample was determined as $70 \sim 80 \mu \mathrm{m}$ by examining the etched cross section of the sample in an optical microscope (Fig. 1a). The through-depth Knoop micro-hardness test revealed that the alpha case layer is harder than the Titanium substrate and the hardness decreases with the increase of depth from the surface (as shown in Fig. 1b). The chemical composition and mechanical properties of the applied material was given in Table 1.
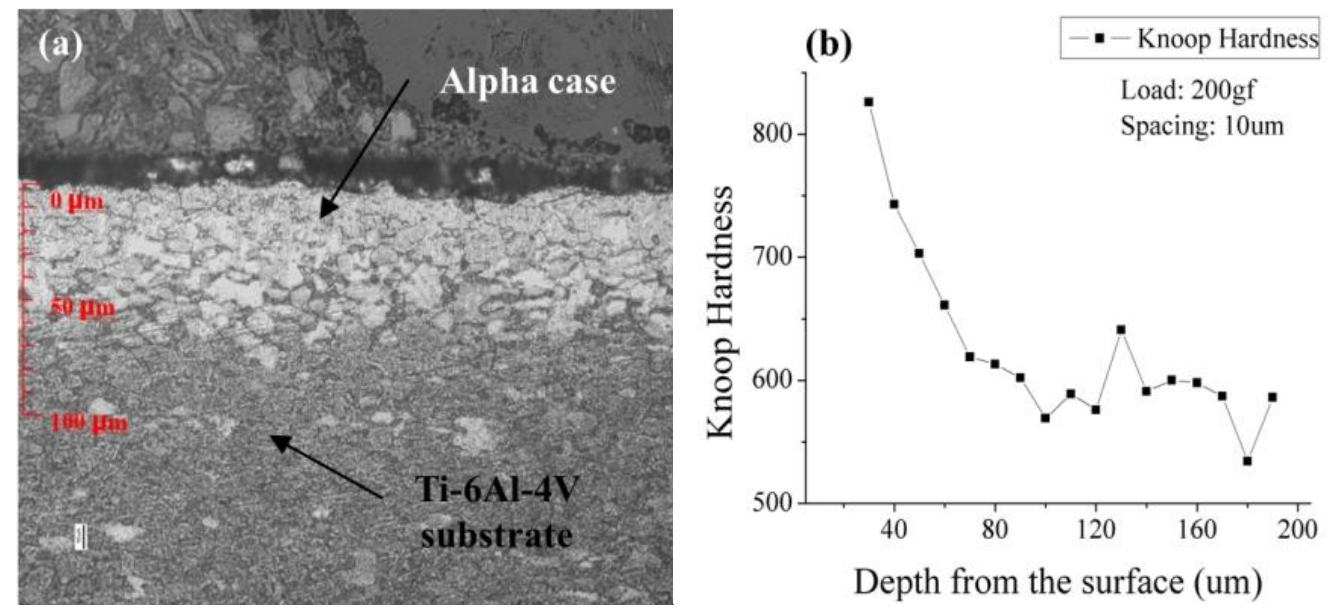

Fig. 1 (a) Cross-section view of the alpha case; (b) Depth profile of the micro hardness.

Table 1 Chemical composition and mechanical properties of titanium alloy

\begin{tabular}{|c|c|c|c|c|c|}
\hline Substrate material & \multicolumn{5}{|c|}{ Ti-6Al-4V } \\
\hline \multirow{4}{*}{$\begin{array}{l}\text { Chemical composition of the } \\
\text { substrate material (in wt. \%) }\end{array}$} & $\mathrm{Al}$ & $\mathrm{V}$ & $\mathrm{Ti}$ & $\mathrm{O}$ & $\mathrm{N}$ \\
\hline & 6.13 & 4 & base & Max 0.02 & Max 0.03 \\
\hline & $\mathrm{H}$ & $\mathrm{Fe}$ & $\mathrm{C}$ & $\mathrm{Y}$ & Others \\
\hline & $\begin{array}{c}\text { Max } \\
0.008\end{array}$ & Max 0.3 & Max 0.8 & $\begin{array}{c}\operatorname{Max} \\
0.005\end{array}$ & Max 0.4 \\
\hline Thickness of the sample (mm) & \multicolumn{5}{|c|}{1} \\
\hline Thickness of alpha case $(\mu \mathrm{m})$ & \multicolumn{5}{|c|}{$70 \sim 80$} \\
\hline Young's modulus (GPa) & \multicolumn{5}{|c|}{110} \\
\hline Poisson's ratio & \multicolumn{5}{|c|}{0.31} \\
\hline Yield stress (MPa) & \multicolumn{5}{|c|}{$925-1180$} \\
\hline
\end{tabular}




\subsection{Experimental Procedure}

\subsubsection{Experiment setup}

In order to investigate the influence of three key waterjet parameters (head pressure, traverse speed and standoff distance) on surface topography and surface residual stress, a full factorial experimental design was applied. Each investigated parameter was assigned three levels so that total of 27 trials was conducted. The range of parametric conditions was described in Table 2. The exposure time, $t_{e}$, which is defined as the exposure time per unit length and is derived from the jet traverse speed, $v$, was used in this study and can be calculated as follows (Soyama et al., 2001):

$$
t_{e}=\frac{n}{v}
$$

where $n$ is the number of passes over the unit length on the work piece. Assuming that the pressure within the jet-impinged area was uniformly distributed and neglecting the spread of the jet along its standoff distance, $n$ can be determined as 4 (jet diameter/ step over). Thus, the corresponding exposure times to the applied jet traverse speeds $(50,120$ and $200 \mathrm{~mm} / \mathrm{min}$ ) are $4.8 \mathrm{~s}, 2 \mathrm{~s}$ and $0.8 \mathrm{~s}$, respectively.

Table 2 Experimental conditions

\begin{tabular}{lll}
\hline Fixed Parameters & Values & \\
\hline Step over & $0.375 \mathrm{~mm}$ & \\
Jet impingement angle & $90^{\circ}$ & \\
Diameter of orifice & $0.3 \mathrm{~mm}$ & \\
Diameter of focusing tube & $1.5 \mathrm{~mm}$ & \\
Entrained air & No & \\
\hline Variable Parameters & Units & Levels \\
\hline Head pressure (P) & $\mathrm{MPa}$ & $138,207,345$ \\
Standoff distance (SOD) & $\mathrm{mm}$ & $5,20,50$ \\
Jet traverse speed $(v)$ & $\mathrm{mm} / \mathrm{min}$ & $50,120,300$ \\
\hline
\end{tabular}

The alpha case removal trials were carried out using an Ormond 5-axis AWJ machining system which is equipped with a KMT Streamline SL-V100D ultra-high pressure intensifier pump. The pump is capable of developing a jet pressure up to $414 \mathrm{MPa}$. A nozzle assembly with a sapphire orifice $(0.3 \mathrm{~mm}$ in diameter) and a Rotec 100 tungsten carbide round-jet focusing tube (1.5 $\mathrm{mm}$ in bore diameter and $76 \mathrm{~mm}$ in length) was utilized. The experimental setup was illustrated in Fig. 2. The specimen was fixed to a steel plate by four screws located at the corners to keep the specimen flat during the PWJ treatment and the following measurements. For each experimental setting, a $8 \mathrm{~mm}$ x $6 \mathrm{~mm}$ area was selectively removed. 
All 27 PWJ-removed surfaces corresponding to the 27 experimental settings were produced on the same specimen. A scanning path was applied for the jet movement to form the surface removal (Fig. 2).
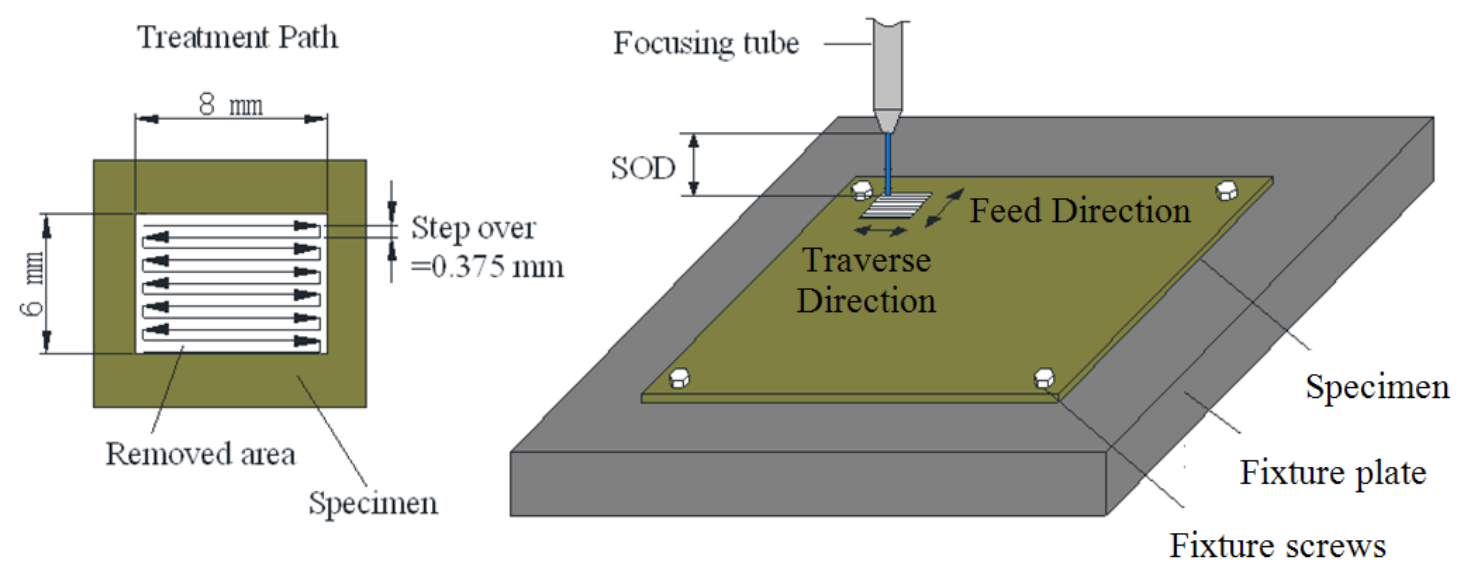

Fig. 2 Schematic illustration of experimental set-up for PWJ alpha case removal

\subsubsection{Surface characterisation}

The PWJ-treated surfaces were measured by non-contact laser profilometer (Talysurf CLI1000) to determine the depth of removal and surface roughness. Selected PWJ-treated surfaces were also examined by a scanning electron microscopy (Philip XL30 FEG-SEM, with an accelerating voltage of $20 \mathrm{kV}$ ). The average roughness, $\mathrm{Ra}$, was used to evaluate the roughness of the removed surfaces. $\mathrm{Ra}$ along the traverse direction $\left(\mathrm{Ra}_{\mathrm{L}}\right)$ and $\mathrm{Ra}$ along the feed direction $\left(\mathrm{Ra}_{\mathrm{T}}\right)$ were both measured. To determine the surface roughness, a sampling length of $4 \mathrm{~mm}$ with a Gaussian filter and a cut-off length of $0.8 \mathrm{~mm}$ were used.

In addition to $\mathrm{Ra}$, the apparent volume of interdigitation $\left(V_{i}\right)$ was also used as another indicator of surface texture. $V_{i}$ is a new parameter which is introduced by Arola and McCain (2000) to evaluate a surface that supports mechanical interlocking. $V_{i}$ is capable of differentiating between positive and negative skewed surfaces with the same surface roughness. $V_{i}$ is of critical importance for PWJ-treated surfaces in applications where improvement of osseointegration, fixation and stability is required, such as medical implants and rough surface where coating will be applied to. The $V_{i}$ can be calculated based on core roughness parameters as follows $\left(M_{r 1}\right.$ and $M_{r 2}$ are defined in hundredths):

$$
V_{i}=\frac{R_{p k} M_{r 1}}{2}+\left(R_{p k}+\frac{R_{k}}{2}\right) \cdot\left(M_{r 2}-M_{r 1}\right)+\left(R_{p k}+R_{k}+\frac{R_{v k}}{2}\right) \cdot\left(1-M_{r 2}\right) \quad \text { E.q. } 2
$$


where $R_{p k}, R_{k}$ and $R_{v k}$ are the reduced peak height, core roughness and reduced valley height, respectively. And $M_{r 1}$ and $M_{r 2}$ are the peak and valley material ratios.

\subsubsection{Residual stress measurement}

The BRUKER D8 DISC X-ray diffractometer with $1 / 4$ circle Eulerian cradle carried out the residual stress measurement on the PWJ-treated surfaces. Copper $k_{\alpha}$ radiation was utilized with a wavelength $(\lambda)$ of $1.5406 \AA$ and beam diameter of $1 \mathrm{~mm}$ at $40 \mathrm{kV}$ and $30 \mathrm{~mA}$. The irritation area of the beam was located at the center of each PWJ-removed surface. Peak positions of the diffraction intensity corresponding to plane (211) were recorded at $\psi$ angles of $0^{\circ}, 20.7^{\circ}, 30^{\circ}, 37.8^{\circ}, 45^{\circ}, 52.2^{\circ}$ and $60^{\circ}$ with $\phi$ angles of $0^{\circ}$ and $90^{\circ}$. Polarisation, Lorentz, absorption, background and $k_{\alpha 2}$ corrections were applied for all diffracted peak intensities. Sliding gravity method was used for locating the positions of diffracted peaks which were further used to determine the lattice plane spacing according to Bragg's law. The residual strain can be given by the theory of linear elasticity:

$$
\begin{gathered}
\varepsilon_{\varphi \psi}=\frac{1+\mathrm{v}}{\mathrm{E}}\left(\sigma_{11} \cos ^{2} \varphi+\sigma_{12} \sin 2 \varphi+\sigma_{22} \sin ^{2} \varphi\right) \sin ^{2} \psi+\frac{1+\mathrm{v}}{\mathrm{E}} \sigma_{33} \cos ^{2} \psi \\
-\frac{\mathrm{v}}{\mathrm{E}}\left(\sigma_{11}+\sigma_{22}+\sigma_{33}\right)+\frac{1+\mathrm{v}}{\mathrm{E}}\left(\sigma_{13} \cos \varphi+\sigma_{23} \sin \varphi\right) \sin 2 \psi
\end{gathered}
$$

where $\mathrm{E}$ and $\mathrm{v}$ correspond to the elastic modulus and Poisson's ratio respectively for the applied material. Due to the small penetration depth of the X-rays in Ti-6Al-4V, a planestress state can be assumed, yielding $\sigma_{33}=0$. Additionally, the shear components $\sigma_{13}, \sigma_{23}$ are only present in surface layers that are plastically deformed by high tangential forces. Thus, E.q. 3 can be simplified to the following equation which evaluates the stress component $\sigma_{\varphi}$ and the sum of principal stresses by a linear fit of the lattice strain- $\sin ^{2} \psi$ distribution.

$$
\varepsilon_{\varphi \psi}=\frac{\mathrm{d}_{\varphi \psi}-\mathrm{d}_{0}}{\mathrm{~d}_{0}}=\frac{1+\mathrm{v}}{\mathrm{E}} \sigma_{\varphi} \sin ^{2} \psi-\frac{\mathrm{v}}{\mathrm{E}}\left(\sigma_{11}+\sigma_{22}\right)
$$

$\sigma_{\varphi}$ is then given by

$$
\sigma_{\varphi}=\sigma_{11} \cos ^{2} \varphi+\sigma_{22} \sin ^{2} \varphi
$$

Thus, a bi-axial in-plane normal stress can be calculated for each PWJ-treated surface with the two applied $\varphi$ angles. Absorption coefficient for the applied material was determined to be $902.5 \mathrm{~cm}^{-1}$ which correspond to an X-ray penetration depth (for the $99 \%$ absorption) of 10 
$\mu \mathrm{m}$. Thus, the residual stresses measured using XRD are determined over the $10 \mu \mathrm{m}$ depth of $\mathrm{X}$-ray penetration.

In order to explore the original residual stress distribution along the depth of untreated Ti$6 \mathrm{Al}-4 \mathrm{~V}$ with alpha case, the depth profile of residual stress was obtained by progressively electrolytic removal of thin layers and subsequent X-ray measurement. The applied electrolyte compose of $6 \mathrm{ml} \mathrm{HClO}_{4}, 35 \mathrm{ml} \mathrm{n}$-butyl alcohol and $60 \mathrm{ml}$ methanol as recommended by Vosough et al. (2005). The sample was etched at $15 \mathrm{~V}$ and room temperature. The current density is $0.07-0.13 \mathrm{~A} / \mathrm{cm}^{2}$ and the removal rate is $8 \mu \mathrm{m}$ approximately.

\section{Results}

\subsection{Microscopic features and surface topography}

The microscopic features of the surface from all PWJ-treated specimens were similar in nature regardless of the experimental conditions used. Characteristics of developed damages being associated with ductile fracture, appearing rough and irregular as observed and analysed by Huang et al. (2012) were clearly evident from the SEM images. Nevertheless, surfaces treated by higher jet energy (higher pressure and/or longer exposure time) exhibited greater degree of irregularity (e.g. presence of deep cavities, valley markings) than that treated by lower jet energy as shown in Fig. 3.
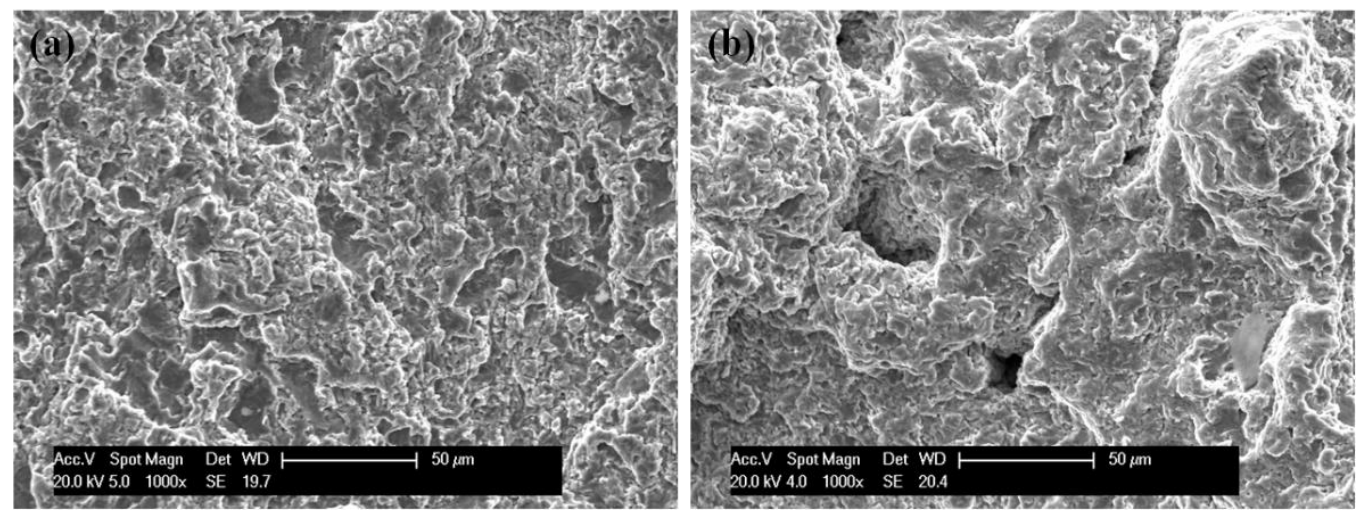

Fig. 3 Microscopic features of Ti-6Al-4V surfaces resulting from PWJ treatment at SOD=50 mm, (a) $P=207 \mathrm{MPa}, \mathrm{t}_{\mathrm{e}}=0.8 \mathrm{~s} ;(\mathrm{b}) \mathrm{P}=345 \mathrm{MPa}, \mathrm{t}_{\mathrm{e}}=4.8 \mathrm{~s}$. 

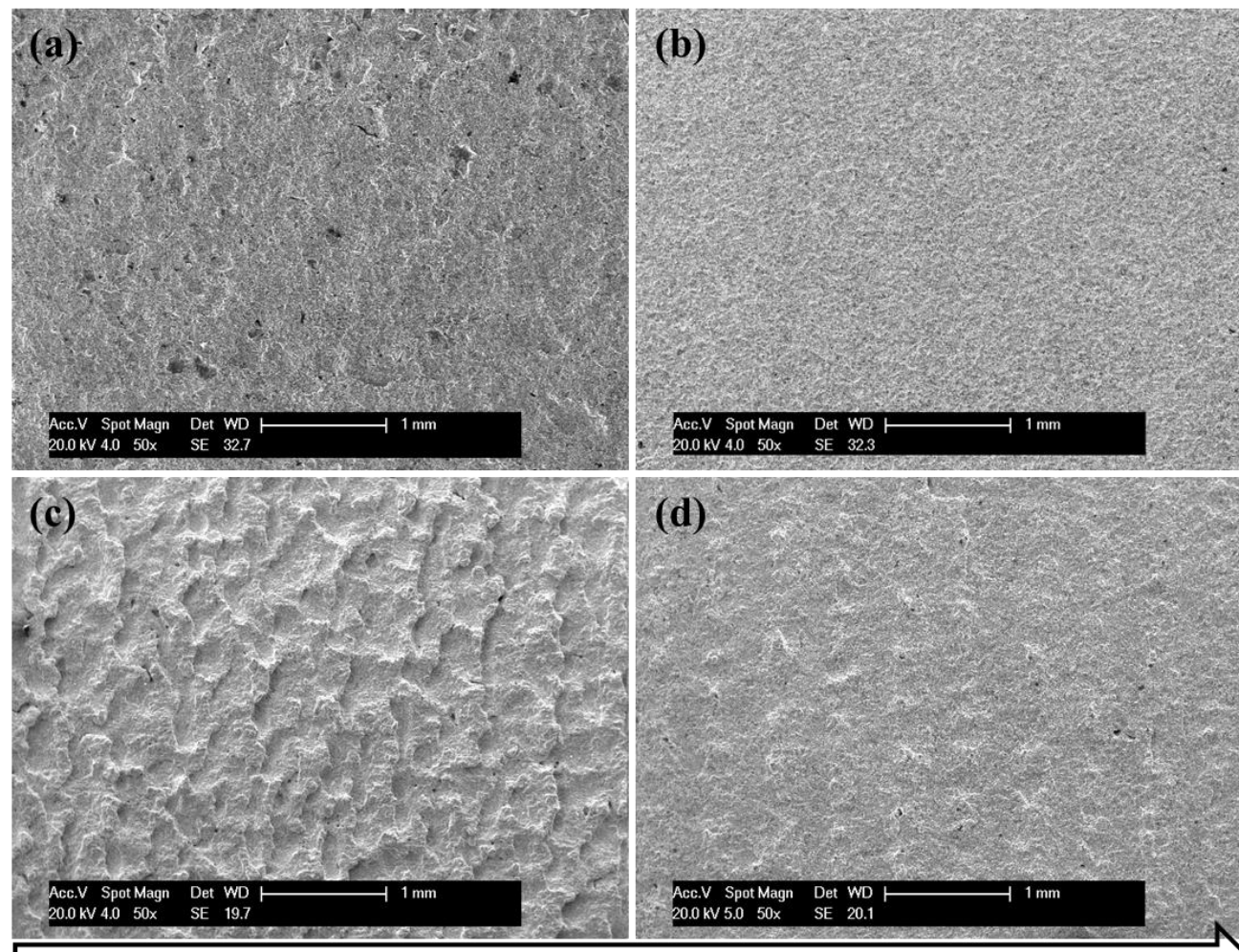

Jet Feed Direction

Fig. 4 Morphological features of Ti-6Al-4V surfaces resulting from PWJ treatment at SOD=50 mm, (a) $P=207 \mathrm{MPa}, \mathrm{t}_{\mathrm{e}}=4.8 \mathrm{~s}$; (b) $\mathrm{P}=207 \mathrm{MPa}, \mathrm{t}_{\mathrm{e}}=0.8 \mathrm{~s}$; (c) $\mathrm{P}=345 \mathrm{MPa}, \mathrm{t}_{\mathrm{e}}=4.8 \mathrm{~s}$; (d) $P=345 \mathrm{MPa}, \mathrm{t}_{\mathrm{e}}=0.8 \mathrm{~s}$.

The removal depth, surface roughness parameters and the interdigitation volume resulting from the alpha case removal treatment using PWJ were listed in Table 3. The range in parametric conditions used for the alpha case removal resulted in significant changes in the surface roughness and corresponding volume for interdigitation. At the lowest applied water head pressure of $207 \mathrm{MPa}$, the removal depths were all below $70 \mu \mathrm{m}$ which indicates that at such pressure the jet is not powerful enough to completely remove the alpha case layer within the experimental conditions. At a water head pressure of $276 \mathrm{MPa}$ or $345 \mathrm{MPa}$, alpha case layer is more likely to be completely removed with a longer exposure time. As both water pressure and exposure time are associated with the energy impinged on the workpiece per unit area, it is clear that the depth of removal increases with the increase of energy impinged per unit area (or energy density).

Table 3 Depth of removal, surface roughness, volume available for interdigitation resulting from PWJ treatment of Ti-6Al-4V with $80 \mu \mathrm{m}$ alpha case layer

\begin{tabular}{|c|c|c|c|c|c|c|c|c|c|c|c|c|}
\hline $\begin{array}{l}\text { Trial } \\
\text { No. }\end{array}$ & $\begin{array}{c}\mathrm{P} \\
(\mathrm{MPa})\end{array}$ & $\begin{array}{l}\text { SOD } \\
(\mathrm{mm})\end{array}$ & $\begin{array}{l}t_{e} \\
(\mathrm{~s})\end{array}$ & $\begin{array}{l}\text { DOR } \\
(\mu \mathrm{m})\end{array}$ & $\begin{array}{c}\mathrm{R}_{\mathrm{pk}} \\
(\mu \mathrm{m})\end{array}$ & $\begin{array}{c}\mathrm{R}_{\mathrm{k}} \\
(\mu \mathrm{m})\end{array}$ & $\begin{array}{c}\mathrm{R}_{\mathrm{vk}} \\
(\mu \mathrm{m})\end{array}$ & $\mathrm{M}_{\mathrm{r} 1}$ & $\mathrm{M}_{\mathrm{r} 2}$ & $\begin{array}{l}\mathrm{Ra}_{\mathrm{T}} \\
(\mu \mathrm{m})\end{array}$ & $\begin{array}{c}\mathrm{Ra}_{\mathrm{L}} \\
(\mu \mathrm{m})\end{array}$ & $\begin{array}{c}V_{i} \\
\left(\mu \mathrm{m}^{3} /\right. \\
\left.\mu \mathrm{m}^{2}\right) \\
\end{array}$ \\
\hline 1 & 207 & 5 & 4.8 & 43.1 & 3.98 & 14.40 & 9.31 & 0.08 & 0.86 & 4.5 & 3.9 & 22.93 \\
\hline 2 & 207 & 5 & 2 & 32.7 & 2.86 & 9.94 & 3.95 & 0.09 & 0.88 & 3.0 & 3.2 & 14.71 \\
\hline 3 & 207 & 5 & 0.8 & 29.5 & 2.89 & 9.62 & 5.13 & 0.08 & 0.87 & 3.0 & 3.3 & 15.01 \\
\hline 4 & 207 & 20 & 4.8 & 64.4 & 6.28 & 20.80 & 15.20 & 0.07 & 0.83 & 6.8 & 6.0 & 34.52 \\
\hline
\end{tabular}




\begin{tabular}{ccccccccccccc}
5 & 207 & 20 & 2 & 28.2 & 4.51 & 12.00 & 4.36 & 0.11 & 0.90 & 3.6 & 3.5 & 18.61 \\
6 & 207 & 20 & 0.8 & 24 & 4.23 & 12.90 & 4.87 & 0.11 & 0.91 & 3.8 & 3.2 & 19.48 \\
7 & 207 & 50 & 4.8 & 68.4 & 9.03 & 20.80 & 7.18 & 0.14 & 0.90 & 6.4 & 7.2 & 33.27 \\
8 & 207 & 50 & 2 & 26.5 & 3.82 & 13.00 & 4.58 & 0.09 & 0.87 & 3.9 & 3.8 & 19.03 \\
9 & 207 & 50 & 0.8 & 19.8 & 3.98 & 10.90 & 4.05 & 0.10 & 0.90 & 3.2 & 3.7 & 16.83 \\
10 & 276 & 5 & 4.8 & 171 & 8.21 & 27.10 & 6.75 & 0.10 & 0.91 & 7.3 & 5.6 & 38.51 \\
11 & 276 & 5 & 2 & 37.2 & 4.51 & 13.10 & 5.79 & 0.11 & 0.90 & 4.1 & 3.7 & 20.41 \\
12 & 276 & 5 & 0.8 & 25.5 & 4.15 & 10.10 & 3.58 & 0.10 & 0.90 & 3.0 & 3.1 & 15.97 \\
13 & 276 & 20 & 4.8 & 424 & 15.20 & 51.80 & 19.80 & 0.09 & 0.87 & 14.7 & 9.3 & 76.56 \\
14 & 276 & 20 & 2 & 95.1 & 6.97 & 22.20 & 8.16 & 0.11 & 0.89 & 6.4 & 6.5 & 33.10 \\
15 & 276 & 20 & 0.8 & 32.4 & 10.10 & 5.82 & 8.76 & 0.09 & 0.88 & 3.6 & 3.3 & 20.23 \\
16 & 276 & 50 & 4.8 & 426 & 13.20 & 41.50 & 23.80 & 0.10 & 0.82 & 14.4 & 12.1 & 66.31 \\
17 & 276 & 50 & 2 & 111 & 14.40 & 24.40 & 11.10 & 0.16 & 0.91 & 7.9 & 7.1 & 44.16 \\
18 & 276 & 50 & 0.8 & 30.7 & 4.83 & 11.10 & 4.21 & 0.11 & 0.90 & 3.4 & 3.4 & 17.96 \\
19 & 345 & 5 & 4.8 & 614 & 11.80 & 57.00 & 41.70 & 0.05 & 0.80 & 18.5 & 14.7 & 89.24 \\
20 & 345 & 5 & 2 & 197 & 7.57 & 25.00 & 7.93 & 0.10 & 0.90 & 6.6 & 4.9 & 36.37 \\
21 & 345 & 5 & 0.8 & 31.9 & 4.78 & 11.60 & 6.26 & 0.09 & 0.86 & 3.6 & 4.4 & 19.43 \\
22 & 345 & 20 & 4.8 & 839 & 22.40 & 73.50 & 26.60 & 0.11 & 0.85 & 23.4 & 18.6 & 108.72 \\
23 & 345 & 20 & 2 & 407 & 10.40 & 30.40 & 21.20 & 0.12 & 0.88 & 10.0 & 7.3 & 51.15 \\
24 & 345 & 20 & 0.8 & 81.7 & 6.38 & 22.80 & 7.67 & 0.09 & 0.90 & 6.6 & 6.7 & 32.86 \\
25 & 345 & 50 & 4.8 & 915 & 35.00 & 80.40 & 32.70 & 0.05 & 0.80 & 24.9 & 17.4 & 131.27 \\
26 & 345 & 50 & 2 & 430 & 9.25 & 32.10 & 19.20 & 0.11 & 0.84 & 9.6 & 8.9 & 50.71 \\
27 & 345 & 50 & 0.8 & 110 & 8.57 & 27.50 & 9.14 & 0.09 & 0.88 & 7.7 & 6.7 & 40.46 \\
\hline
\end{tabular}

The average surface roughness $(\mathrm{Ra})$ resulting from the PWJ removal treatment was measured along two directions as clarified before. It was found from Table 3 that, generally, the average surface roughness along the jet feed direction $\left(\mathrm{Ra}_{\mathrm{T}}\right)$ was higher than that along the traverse direction $\left(\mathrm{Ra}_{\mathrm{L}}\right)$ for surfaces with high $\mathrm{Ra}$ values. In contrast, the PWJ-treated surfaces with lower $\mathrm{Ra}$ values exhibited a $\mathrm{Ra}_{\mathrm{T}}$ equal to, or even lower than the $\mathrm{Ra}_{\mathrm{L}}$. It was also found that there is high linear correlation between $\mathrm{Ra}_{\mathrm{T}}$ and $\mathrm{Ra}_{\mathrm{L}}$ (as shown in Fig. 5a). This indicates that the investigated process parameters resulted in similar parametric trends on the average surface roughness along both directions. The highest $\mathrm{Ra}_{\mathrm{T}}$ and $\mathrm{Ra}_{\mathrm{L}}$ observed were $24.9 \mu \mathrm{m}$ and $18.6 \mu \mathrm{m}$, respectively, and both resulted from treatment with the highest pressure $(345 \mathrm{MPa})$ and lowest traverse speed as evident from Table 3. Despite the large maximum Ra values, the Ra of most of PWJ-removed surfaces was below $10 \mu \mathrm{m}$. It can be clearly seen from Table 3 that higher pressure and/or longer exposure time were more likely to lead to higher average surface roughness which was supported by the microscope features of the surfaces as shown in Fig. 4. According to the similar parametric trends for the removal depth and average surface roughness, an increase in $\mathrm{Ra}$ is possible with a corresponding increase in the removal depth. A linear relationship between them was verified by Fig. $5 \mathrm{~b}$. Fig. $5 b$ also revealed that the difference between $\mathrm{Ra}_{\mathrm{T}}$ and $\mathrm{Ra}_{\mathrm{L}}$ increases with the increase of removal depth. 

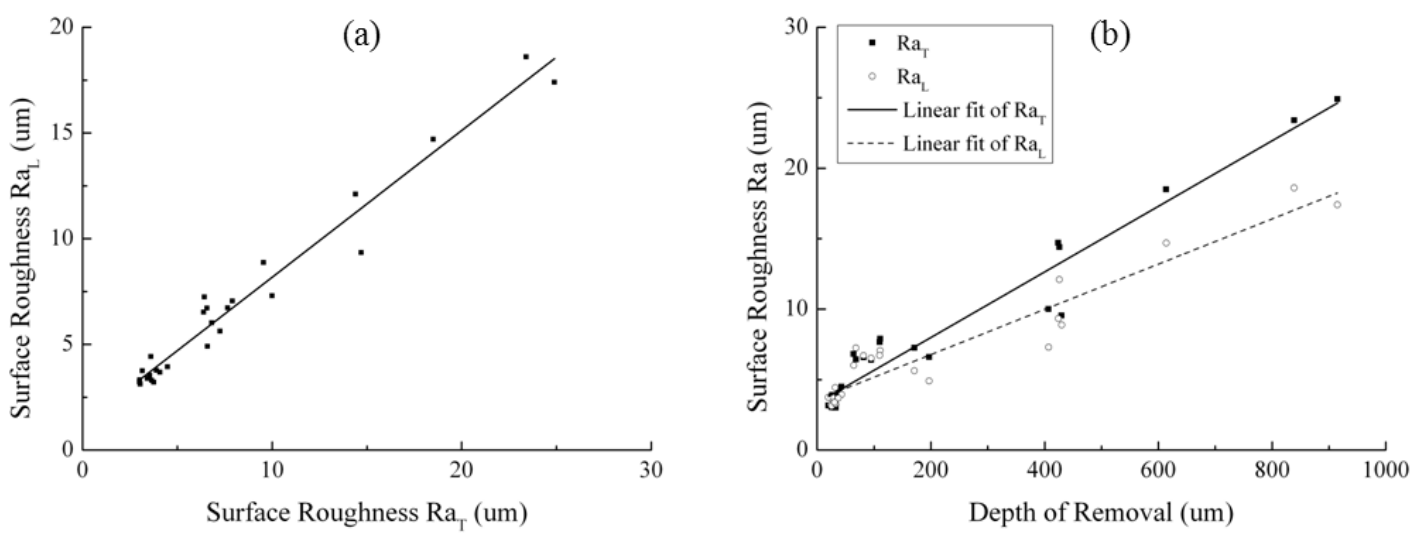

Fig. 5 Correlation between (a) RaT and RaL; (b) Ra and DOR.

The apparent volume for interdigitation $\left(\mathrm{V}_{\mathrm{i}}\right)$ as shown in Table 3 was calculated according to E.q. 2 using the core surface roughness parameters. As expected, the PWJ-removed surface with the largest $V_{i}$ resulted from the highest water pressure and longest exposure time. This is consistent with the trend in the average surface roughness Ra. Fig. 6 shows the influence of water head pressure and exposure time on the interdigitation volume and the corresponding average surface roughness at a standoff distance of $50 \mathrm{~mm}$. It was clear that there is an equivalent parametric trend for the $\mathrm{Ra}$ and $\mathrm{V}_{\mathrm{i}}$. Thus, the increase in exposure time and/or pressure resulted in an increase in the apparent volume for interdigitation.

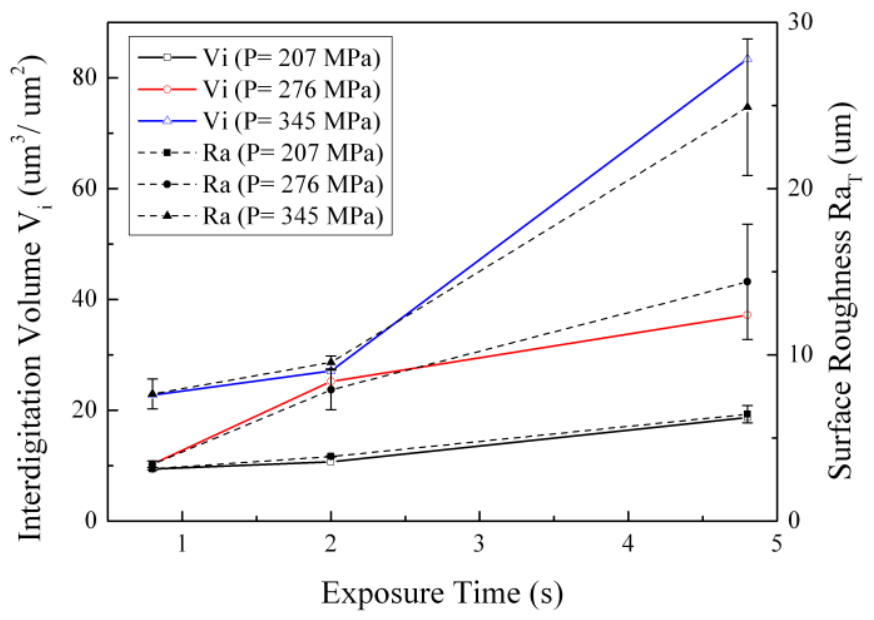

Fig. 6 Exposure time vs. $R a$ and $V_{i}$ at $S O D=50 \mathrm{~mm}$ with varying pressures

\subsection{Residual stress}

The bi-axial in-plane normal stresses resulting from electro-chemically removed and PWJremoved samples were calculated using the $\sin ^{2} \psi$ method according to E.q. 4 and E.q. 5 at transversal $\left(\varphi=90^{\circ}\right)$ and longitudinal $\left(\varphi=0^{\circ}\right)$ directions (as illustrated in Fig. 2), and were 
marked as $\sigma_{\mathrm{T}}$ and $\sigma_{\mathrm{L}}$, respectively. The depths of electro-chemically etched samples resulting from progressively removal were shown in Fig. 7a. Fig. $7 \mathrm{~b}$ reveals the residual stress distribution along the depth of original material by measuring these electro-chemically etched samples at different depths of removal. As evident from Fig. 7b, the biaxial residual stresses on the top of original material (top of alpha case) were both found to be tensile with magnitudes of $146 \pm 48 \mathrm{MPa}$ and $124 \pm 41 \mathrm{MPa}$, respectively. With increase in the depth the magnitudes of average residual stresses in both directions slightly decrease and tend to be stabilized at a level which is very close to $0 \mathrm{MPa}$ when the depth is above $60-80 \mu \mathrm{m}$. In light of the thickness of alpha case layer, it can be concluded that the residual stress presented in the alpha case is tensile and declines with increasing depth from the surface despite there are some variations.
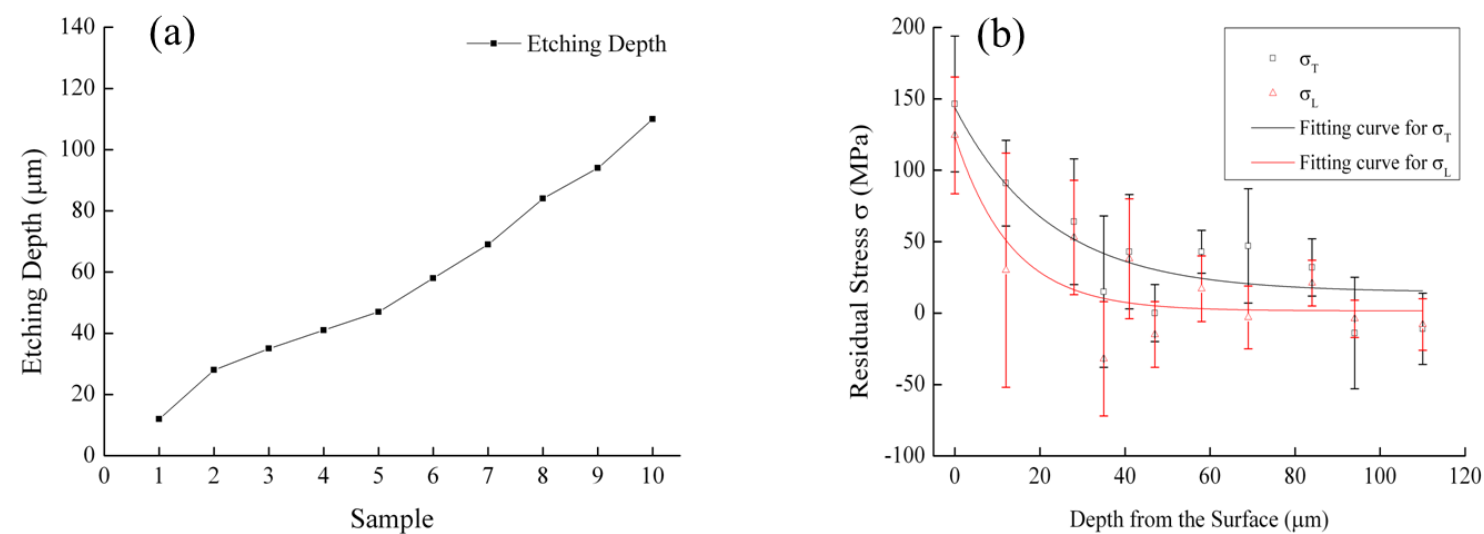

Fig. 7 (a) Depths of electro-chemically etched samples resulting from progressively removal; (b) Residual stress distribution below the surface in original material.

The biaxial stresses formed during PWJ treatment under all experimental conditions are listed in Table 4. It was found that the residual stress resulting from all experimental conditions of PWJ treatment were compressive; the magnitude of the average residual stress ranged from 18 to $-563 \mathrm{MPa}$ and was dependent on the treatment conditions. It is interesting that the largest compressive residual stress observed resulted from PWJ trial No. 5, which uses the lowest applied water head pressure and an intermediate standoff distance and exposure time. Furthermore, for a constant standoff distance, the shortest exposure time resulted in the lowest compressive residual stress at the pressure of $207 \mathrm{MPa}$; in contrast, at higher water pressures of $276 \mathrm{MPa}$ and $345 \mathrm{MPa}$, the shortest exposure time always resulted in the highest residual stress. 
Table 4 Biaxial residual stress resulting from PWJ treatment of Ti-6Al-4V with $80 \mu \mathrm{m}$ alpha case layer

\begin{tabular}{cccccccc}
\hline Trial No. & $\begin{array}{c}P \\
(\mathrm{MPa})\end{array}$ & $\begin{array}{c}S O D \\
(\mathrm{~mm})\end{array}$ & $\begin{array}{c}t_{e} \\
(\mathrm{~s})\end{array}$ & $\begin{array}{c}\sigma_{L} \\
\mathrm{MPa}\end{array}$ & $\begin{array}{c}\sigma_{L} \text { Error } \\
\mathrm{MPa}\end{array}$ & $\begin{array}{c}\sigma_{T} \\
\mathrm{MPa}\end{array}$ & $\begin{array}{c}\sigma_{T} \text { Error } \\
\mathrm{MPa}\end{array}$ \\
\hline 1 & 207 & 5 & 4.8 & -469 & \pm 51 & -528 & \pm 35 \\
2 & 207 & 5 & 2 & -427 & \pm 51 & -443 & \pm 33 \\
3 & 207 & 5 & 0.8 & -351 & \pm 53 & -269 & \pm 27 \\
4 & 207 & 20 & 4.8 & -457 & \pm 86 & -398 & \pm 72 \\
5 & 207 & 20 & 2 & -563 & \pm 76 & -468 & \pm 30 \\
6 & 207 & 20 & 0.8 & -325 & \pm 74 & -405 & \pm 44 \\
7 & 207 & 50 & 4.8 & -406 & \pm 24 & -350 & \pm 15 \\
8 & 207 & 50 & 2 & -538 & \pm 43 & -472 & \pm 30 \\
9 & 207 & 50 & 0.8 & -256 & \pm 113 & -335 & \pm 44 \\
10 & 276 & 5 & 4.8 & -257 & \pm 47 & -209 & \pm 16 \\
11 & 276 & 5 & 2 & -477 & \pm 30 & -468 & \pm 16 \\
12 & 276 & 5 & 0.8 & -551 & \pm 68 & -423 & \pm 55 \\
13 & 276 & 20 & 4.8 & -175 & \pm 43 & -225 & \pm 6 \\
14 & 276 & 20 & 2 & -279 & \pm 22 & -310 & \pm 14 \\
15 & 276 & 20 & 0.8 & -562 & \pm 53 & -520 & \pm 31 \\
16 & 276 & 50 & 4.8 & -224 & \pm 23 & -226 & \pm 22 \\
17 & 276 & 50 & 2 & -362 & \pm 20 & -276 & \pm 13 \\
18 & 276 & 50 & 0.8 & -465 & \pm 64 & -512 & \pm 31 \\
19 & 345 & 5 & 4.8 & -29 & \pm 26 & -170 & \pm 14 \\
20 & 345 & 5 & 2 & -211 & \pm 26 & -247 & \pm 5 \\
21 & 345 & 5 & 0.8 & -415 & \pm 59 & -493 & \pm 28 \\
22 & 345 & 20 & 4.8 & -18 & \pm 39 & -158 & \pm 17 \\
23 & 345 & 20 & 2 & -162 & \pm 20 & -200 & \pm 20 \\
24 & 345 & 20 & 0.8 & -322 & \pm 46 & -298 & \pm 28 \\
25 & 345 & 50 & 4.8 & -138 & \pm 42 & -118 & \pm 12 \\
26 & 345 & 50 & 2 & -205 & \pm 33 & -186 & \pm 34 \\
27 & 345 & 50 & 0.8 & -224 & \pm 32 & -234 & \pm 25 \\
\hline
\end{tabular}

Fig. 8 shows the influence of water pressure and exposure time on residual stress introduced by PWJ treatment at a constant standoff distance of $50 \mathrm{~mm}$. Comparing Fig. 8a and Fig. 8b, it was found that residual stresses at transversal and longitudinal direction have similar parametric trends. Higher water pressure generally resulted in lower compressive residual stress, with an exception of that at an exposure time of $0.8 \mathrm{~s}$, a water pressure of $276 \mathrm{MPa}$ resulted in the largest compressive residual stress. With the increase of exposure time per unit length, the residual stress introduced decreased gradually for pressures of $276 \mathrm{MPa}$ and 345 MPa. However, at the lowest pressure of $207 \mathrm{MPa}$, with the increase of exposure time, the compressive residual stress firstly increased to a potential maximum value at $2 \mathrm{~s}$ of exposure time, and then decreased with further increase of exposure time. In light of this, if shorter exposure times were applied at higher water pressures, the maximum value of compressive residual stress may be also obtained. 

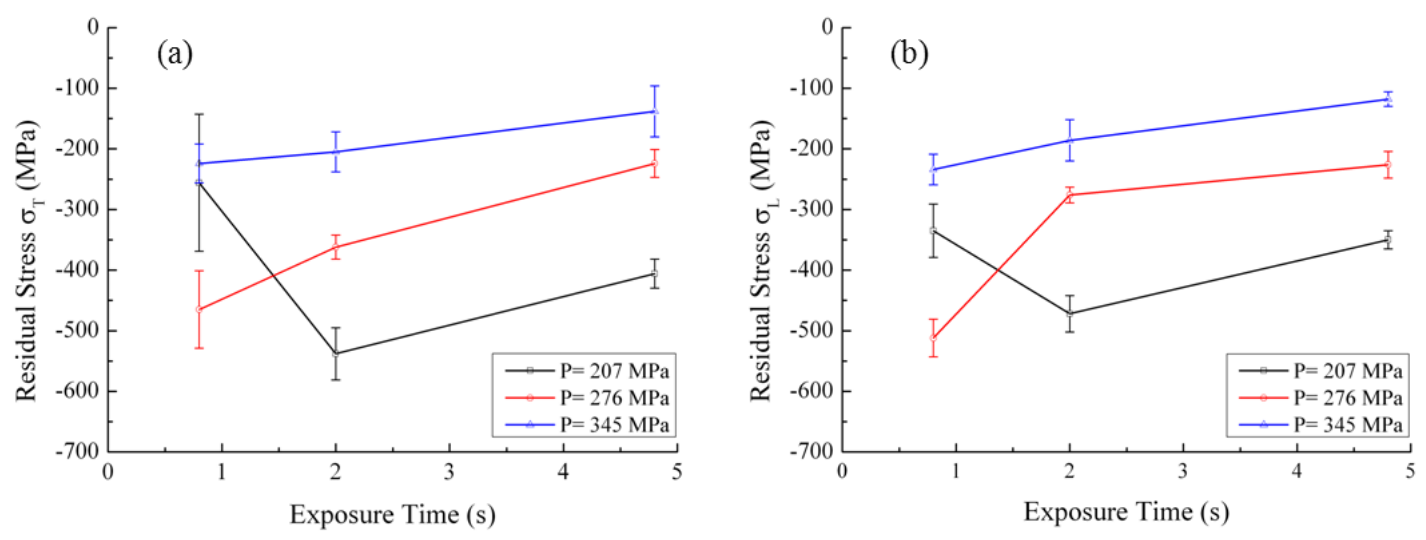

Fig. 8 Influence of water pressure and exposure time on residual stresses within PWJ-treated surfaces at a standoff distance of $50 \mathrm{~mm}$ : (a) residual stress at transversal direction; (b) residual stress at longitudinal direction

In order to comprehensively understand the influence of waterjet parameters on the compressive residual stress introduced during PWJ alpha case removal process, three separate trails were carried out in addition to the scope of experimental design. These three additional trials were conducted using the same water pressure and standoff distance as that used for trial No. 25-27, but with shorter exposure times ( $0.48 \mathrm{~s}, 0.24 \mathrm{~s}$ and $0.12 \mathrm{~s}$, respectively). In this case, the change of PWJ-introduced residual stress over a larger range of exposure time per unit length (or energy impinged per unit length) can be obtained. The resulted residual stress and corresponding average surface roughness were shown in Fig. 9a. It can be seen that with the increase of exposure time the compressive residual stress has a sharp increase until it reaches a maximum; with further increase of exposure time the compressive stress decreases significantly. However, there is a specific value for the exposure time above which the decrease of compressive residual stress becomes slow. Fig. 9a also shows that the two directional residual stresses have very similar parametric trend under the influence of exposure time. Fig. 9b shows the corresponding removal depths resulting from the same experimental conditions. It can be seen from Fig. 9a and $\mathrm{b}$ that with shorter exposure times which resulted in removal depths less than the thickness of alpha case layer (as shown in Fig. $9 b)$, the compressive residual stress increased with the increase of removal depth. In contrast, with longer exposure times which render the jet powerful enough to completely remove the alpha case, the compressive residual stress decreased with the increase of removal depth. 

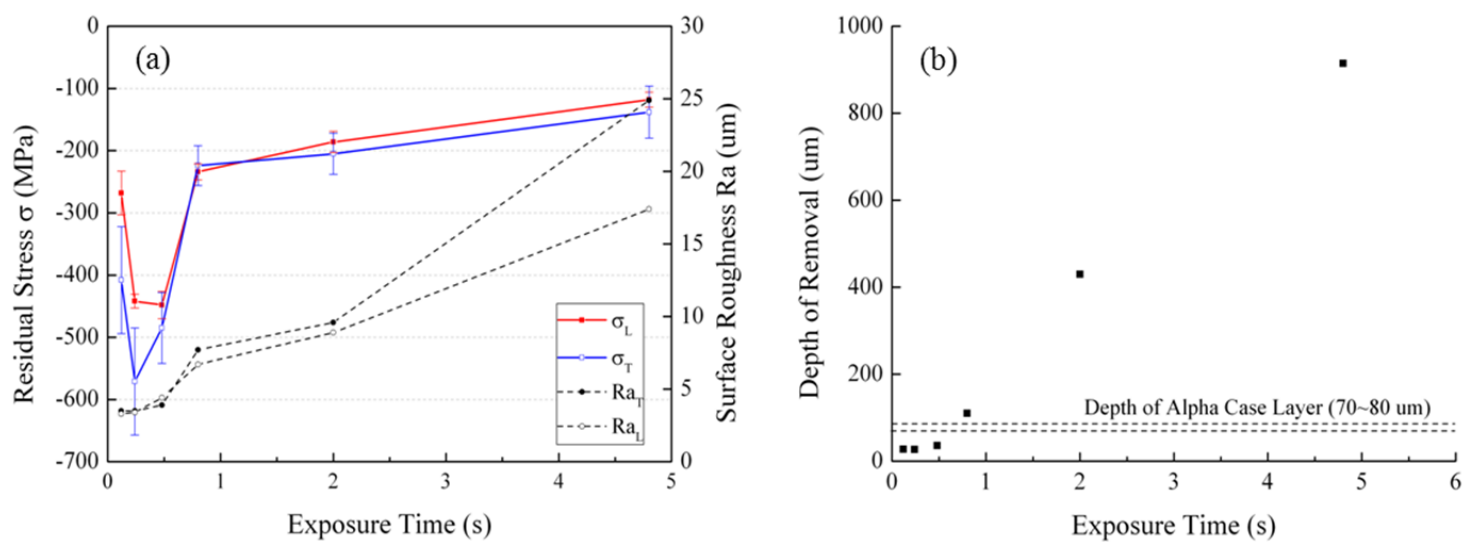

Fig. 9 (a) Residual stresses; and (b) depth of removal resulting from PWJ treatment at water pressure of 345 MPa and standoff distance of $50 \mathrm{~mm}$.

\subsection{ANOVA Analysis}

In order to determine the significant PWJ parameters affecting the depth of removal, average surface roughness, volume for interdigitation and the residual stress and their relative contributions, analysis of variance (ANOVA) and $F$-test were used as suggested by Caydas and Hascalik (2008). Table 5 shows the results of ANOVA. Larger $F$ value indicates that the variation of PWJ parameter makes greater change on the process output. The $F$ values at significance levels $(\alpha)$ of 0.01 and 0.05 were used as the references which can be determined by the $F$-distribution table according to the degree of freedom. As $F_{0.05}(2,20)$ is 3.4928 and $F_{0.01}(2,20)$ is 5.849 , if $F<F_{0.05}$, the effect of PWJ parameter on process output is insignificant (marked with ${ }^{\mathrm{ns}}$ ); if $F_{0.05} \leq F<F_{0.01}$, the PWJ parameter has statistic influence on the process output (marked with $*$ ); if $F \geq F_{0.01}$, the PWJ parameter has significant influence on the process output (marked with $* *$ ). Thus, as clearly shown in Table 5, the standoff distance has insignificant effects on all investigated process outputs, while the water pressure and jet traverse speed both have significant effects on the depth of removal, average surface roughness as well as interdigitation volume. Regarding to the residual stress, water pressure has an utmost importance and traverse speed has a statistic influence. The relative contributions of PWJ parameters used in this study on the process outputs were shown in Fig. 10 .

Table 5 Analysis of Variance for depth of removal, surface roughness, volume for interdigitation and residual stresses

\begin{tabular}{cccccc}
\hline \multicolumn{2}{l}{ Results of ANOVA for DOR } & & & \\
\hline $\begin{array}{c}\text { Machining } \\
\text { Parameters }\end{array}$ & $\begin{array}{c}\text { Degree of freedom } \\
(\mathrm{DF})\end{array}$ & $\begin{array}{c}\text { Sum of squares } \\
\left(\mathrm{SS}_{\mathrm{A}}\right)\end{array}$ & $\begin{array}{c}\text { Mean Squares } \\
(\mathrm{MS})\end{array}$ & $\mathrm{F}$ & Contributions \\
\hline$P$ & 2 & 630206 & 315103 & $14.54^{* *}$ & $36.8 \%$ \\
$S O D$ & 2 & 59091 & 29546 & $1.36^{\mathrm{ns}}$ & $3.5 \%$
\end{tabular}




\begin{tabular}{|c|c|c|c|c|c|}
\hline $\begin{array}{c}v_{t} \\
\text { Error } \\
\text { Total } \\
\end{array}$ & $\begin{array}{c}2 \\
20 \\
26 \\
\end{array}$ & $\begin{array}{r}589196 \\
433465 \\
1711958 \\
\end{array}$ & $\begin{array}{l}294598 \\
21673\end{array}$ & $13.59^{* *}$ & $\begin{array}{l}34.4 \% \\
25.3 \%\end{array}$ \\
\hline \multicolumn{6}{|c|}{ Results of ANOVA for Ra (L) } \\
\hline $\begin{array}{l}\text { Machining } \\
\text { Parameters }\end{array}$ & $\begin{array}{c}\text { Degree of freedom } \\
\text { (DF) }\end{array}$ & $\begin{array}{c}\text { Sum of squares } \\
\left(\mathrm{SS}_{\mathrm{A}}\right)\end{array}$ & $\begin{array}{c}\text { Mean Squares } \\
(\mathrm{MS})\end{array}$ & $\mathrm{F}$ & Contributions \\
\hline$P$ & 2 & 155.04 & 77.52 & $16.24^{* *}$ & $31.8 \%$ \\
\hline$S O D$ & 2 & 32.86 & 16.43 & $3.44^{\mathrm{ns}}$ & $6.7 \%$ \\
\hline$v_{t}$ & 2 & 203.67 & 101.84 & $21.33^{* *}$ & $41.8 \%$ \\
\hline Error & 20 & 95.47 & 4.77 & & $19.6 \%$ \\
\hline Total & 26 & 487.04 & & & \\
\hline \multicolumn{6}{|c|}{ Results of ANOVA for Ra $(\mathrm{T})$} \\
\hline $\begin{array}{l}\text { Machining } \\
\text { Parameters }\end{array}$ & $\begin{array}{c}\text { Degree of freedom } \\
\text { (DF) }\end{array}$ & $\begin{array}{c}\text { Sum of squares } \\
\left(\mathrm{SS}_{\mathrm{A}}\right)\end{array}$ & $\begin{array}{c}\text { Mean Squares } \\
(\mathrm{MS})\end{array}$ & $\mathrm{F}$ & Contributions \\
\hline$P$ & 2 & 300.16 & 150.08 & $15.30^{* *}$ & $30.8 \%$ \\
\hline$S O D$ & 2 & 52.28 & 26.14 & $2.66^{\mathrm{ns}}$ & $5.4 \%$ \\
\hline$v_{t}$ & 2 & 427.19 & 213.60 & $21.78^{* *}$ & $43.8 \%$ \\
\hline Error & 20 & 196.17 & 9.81 & & $20.1 \%$ \\
\hline Total & 26 & 975.80 & & & \\
\hline \multicolumn{6}{|c|}{ Results of ANOVA for $V_{i}$} \\
\hline $\begin{array}{l}\text { Machining } \\
\text { Parameters }\end{array}$ & $\begin{array}{c}\text { Degree of freedom } \\
\text { (DF) }\end{array}$ & $\begin{array}{c}\text { Sum of squares } \\
\left(\mathrm{SS}_{\mathrm{A}}\right)\end{array}$ & $\begin{array}{c}\text { Mean Squares } \\
(\mathrm{MS})\end{array}$ & $\mathrm{F}$ & Contributions \\
\hline$P$ & 2 & 2521.1 & 1260.5 & $12.59^{* *}$ & $30 \%$ \\
\hline$S O D$ & 2 & 542.0 & 271.0 & $2.71^{\mathrm{ns}}$ & $6.4 \%$ \\
\hline$v_{t}$ & 2 & 3353.7 & 1676.8 & $16.75^{* *}$ & $40 \%$ \\
\hline Error & 20 & 2002.1 & 100.1 & & $23.8 \%$ \\
\hline Total & 26 & 8418.9 & & & \\
\hline \multicolumn{6}{|c|}{ Results of ANOVA for $\sigma_{\varphi=0^{\circ}}$} \\
\hline $\begin{array}{l}\text { Machining } \\
\text { Parameters }\end{array}$ & $\begin{array}{c}\text { Degree of freedom } \\
\text { (DF) }\end{array}$ & $\begin{array}{c}\text { Sum of squares } \\
\left(\mathrm{SS}_{\mathrm{A}}\right)\end{array}$ & $\begin{array}{c}\text { Mean Squares } \\
(\mathrm{MS})\end{array}$ & $\mathrm{F}$ & Contributions \\
\hline$P$ & 2 & 141827 & 70913 & $7.23^{* *}$ & $33.5 \%$ \\
\hline$S O D$ & 2 & 16261 & 8130 & $0.83^{\mathrm{ns}}$ & $3.8 \%$ \\
\hline$v_{t}$ & 2 & 69421 & 34710 & $3.54^{*}$ & $16.4 \%$ \\
\hline Error & 20 & 196210 & 9810 & & $46.3 \%$ \\
\hline Total & 26 & 423717 & & & \\
\hline \multicolumn{6}{|c|}{ Results of ANOVA for $\sigma_{\varphi=90^{\circ}}$} \\
\hline $\begin{array}{l}\text { Machining } \\
\text { Parameters }\end{array}$ & $\begin{array}{c}\text { Degree of freedom } \\
\text { (DF) }\end{array}$ & $\begin{array}{c}\text { Sum of squares } \\
\left(\mathrm{SS}_{\mathrm{A}}\right)\end{array}$ & $\begin{array}{c}\text { Mean Squares } \\
(\mathrm{MS})\end{array}$ & $\mathrm{F}$ & Contributions \\
\hline$P$ & 2 & 263726 & 131863 & $10.00^{* *}$ & $41.7 \%$ \\
\hline$S O D$ & 2 & 9006 & 4503 & $0.34^{\mathrm{ns}}$ & $1.4 \%$ \\
\hline$v_{t}$ & 2 & 105571 & 52785 & $4.00^{*}$ & $16.7 \%$ \\
\hline Error & 20 & 263820 & 13191 & & $41.7 \%$ \\
\hline Total & 26 & 632123 & & & \\
\hline
\end{tabular}




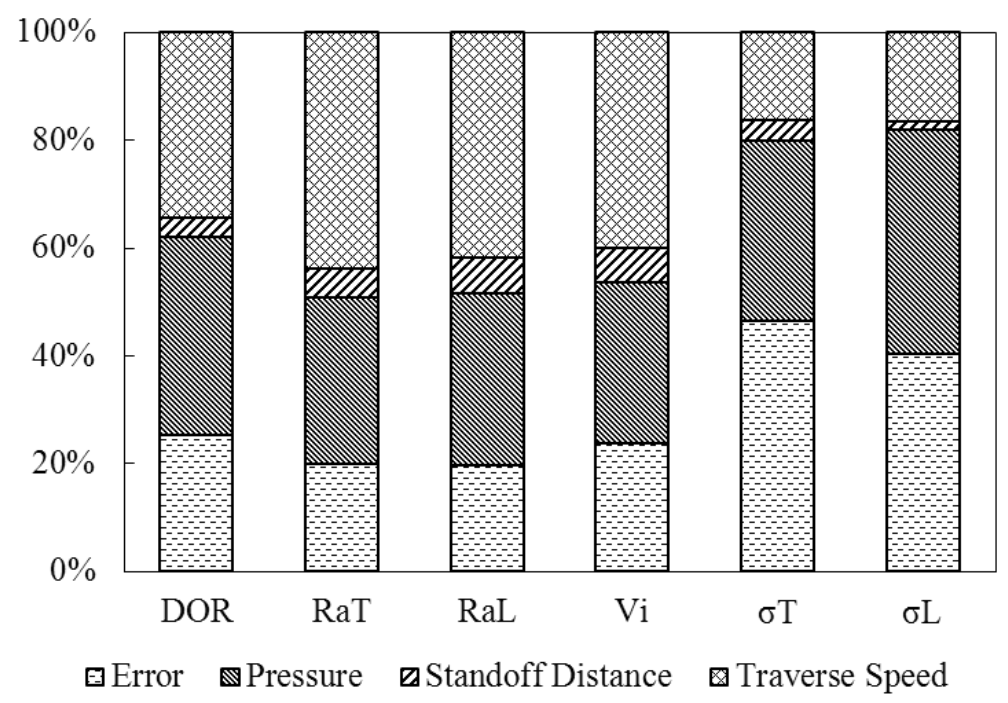

Fig. 10 The relative effect of PWJ parameters on the DOR, average surface roughness, interdigitation volume and residual stress.

\section{Discussion}

The result of residual stress measurement shows that PWJ is capable to remove hard alpha case layer and simultaneously introduce compressive residual stress to the treated surface. However, the influence of waterjet parameters on the residual stress shows some distinct features (as shown in Fig. 9a) compared with that reported by Soyama (2004) and Soyama et al. (2004) in their residual stress studies on waterjet peening of similar materials. The present study and the work conducted by Soyama (2004) may be correlated by the famous erosiontime curve given by Brunton and Rochester (1979). Brunton and Rochester (1979) categorized the liquid impact on a ductile metal into three stages according to the exposure time. Stage I is the incubation period during which there is no detectable material loss, although there will be some plastic or brittle deformation of the surface. After this incubation period, the material will be removed at maximum rate and this period is called Stage II. In Stage III, the erosion rate begins to decrease and tend to a lower and approximate constant rate. Thus, Soyama (2004) actually investigated the influence of exposure time on residual stress resulting from waterjet peening of Ti-6Al-4V during the incubation period (Stage I). As the exposure time increased, the magnitude of deformation increased. This consequently resulted in work hardening over the impact area and an increase in compressive residual stress. After a time, the compressive residual stress reached the maximum and began to decrease slightly with further increase of exposure time. The slight decrease of residual stress may be a result of increasing surface roughness due to plastically-formed depressions. As the water pressure used was very low (30 MPa) compared with that used in this study, the jet was 
not powerful enough to cause material removal. Thus, there was no sharp decrease of compressive residual stress observed by Soyama (2004). In contrast to the work of Soyama (2004), Fig. 9a shows the influence of exposure time on the compressive residual stress introduced during Stage II and Stage III.

It is reasonable to deduce from the result of Soyama (2004) that in Stage II and Stage III of erosion the compressive residual stress should decrease continuously since the removal of surface layers will contribute to the near-surface stress relief. However, Fig. 9a shows an unexpected sharp increase of compressive residual stress at shorter exposure times before the curve turns to the expected trend. Considering that the removal depths resulting from PWJ treatment at these shorter exposure times are all below the thickness of alpha case (Fig. 9b), the decline trend of the compressive residual stress at short exposure times could be due to the existence of alpha case layer. Patankar and Tan (2001) have proved that the alpha case coating has little or no influence on the mechanical properties such as ultimate tensile strength and yield strength but the ductility of the material. In the alpha case layer, diffusion of oxygen leads to the lowering of the overall ductility of the Ti-6Al-4V alloy because smaller oxygen atoms tend to occupy the interstitial sites; and also, these oxygen rich sites serve as stress concentration sites which eventually cause the oxygen rich zone to crack leading to the failure of the alloy at lower strain as claimed by Patankar and Tan (2001). Although the alpha case layer in the examined material is very thin compared to the thickness of the metal sheet, the contents of oxygen along its depth vary. Near-surface layer tends to obtain higher content of oxygen during the generation of alpha case so that become more brittle than layers away from the surface. Consequently, the brittleness determines the maximum strain of materials before failure. Higher brittleness results in the failure of material at lower maximum strain. Thus, within the thickness of alpha case, the maximum strain before material failure is higher away from the surface than it is near the surface. In the case of removing alpha case using PWJ, if the depth of removal is below the depth of alpha case, the surface residual stress

As mentioned, the alpha case is brittle and hard, and plastic deformation is unlikely to occur on brittle materials. However, the micro hardness measurement as shown in Fig. 1b indicates that the properties of the alpha case layer may be proportional to its depth. The near-surface layer of alpha case may be more brittle than that away from the surface. This consequently resulted in lower magnitude of inelastic deformation and compressive residual stress can be 
produced during PWJ impacts. It can be seen from Fig. 9b that the maximum compressive residual stress seems to be reached when the PWJ is just capable to completely remove the alpha case layer without remove too much material from the Ti-6Al-4V substrate. After the exposure time resulting in the maximum compressive residual stress, the material properties have no further influence on the magnitude of residual stress introduced as no alpha case layer remained. With further increasing exposure time, the magnitude of stress relief increased so that the compressive residual stress decreased. Fig. 11 shows the correlation between removal depth and residual stress by plotting the measurement data for all experimental trials. The influence of removal depth on the residual stress is apparent which provides support to above discussion.

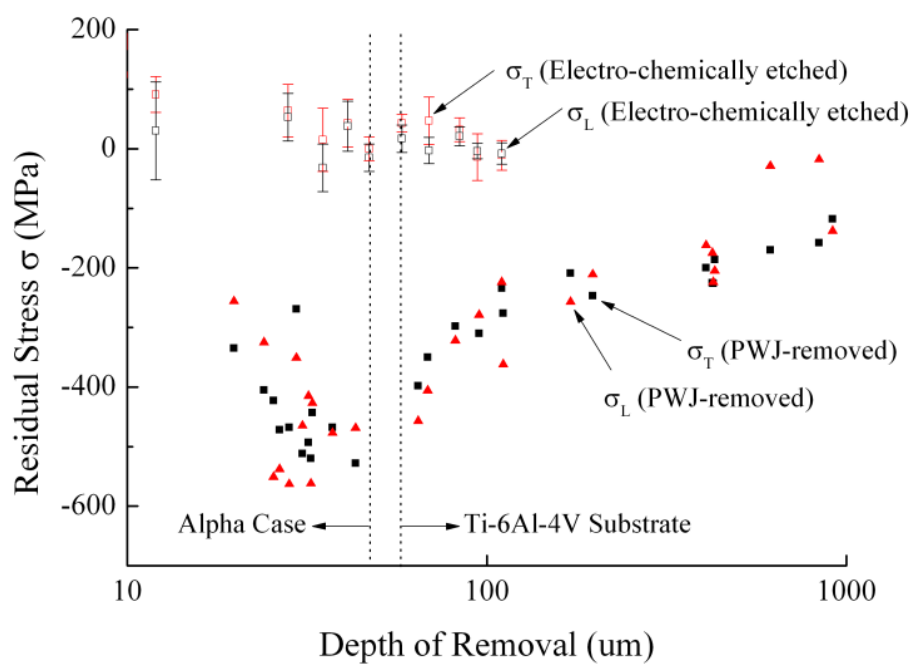

Fig. 11 Correlation between removal depth and residual stress resulting from PWJ treatment.

The maximum compressive stress shown in Fig. 9a $(-571 \mathrm{MPa})$ is much smaller than that observed by Soyama (2004) on the peened Ti-6Al-4V surface (approx. -1000 MPa). This indicates that the compressive residual stress resulting from PWJ removal process may always lower than the maximum of that resulting from PWJ peening process since stress relief in the removal process is inevitable. However, Fig. 9a shows that it is quite possible to remove the alpha case layer simultaneous to introduce an optimum compressive surface residual stress.

Doig and Flewitt (1981) found that the surface texture of the PWJ-removed surfaces resulting from the scanning jet movement path could cause a slight reduction of the residual stress with increasing surface roughness. Thus, it is necessary to evaluate the potential contribution of roughness to the residual stress. As mentioned, the XRD-measured residual stress is the sum 
of the contributions from a small diffracting volume over the depth of X-ray penetration. If the surface is smooth the surface region will contribute more strongly than a deeper region of the same thickness, while Buhrke et al. (1998) showed that if the surface is rough asperities will contribute more strongly than depressions. Fig. 12 shows the possible correlation between the average surface roughness $\mathrm{Ra}_{\mathrm{T}}$ and the residual stress.

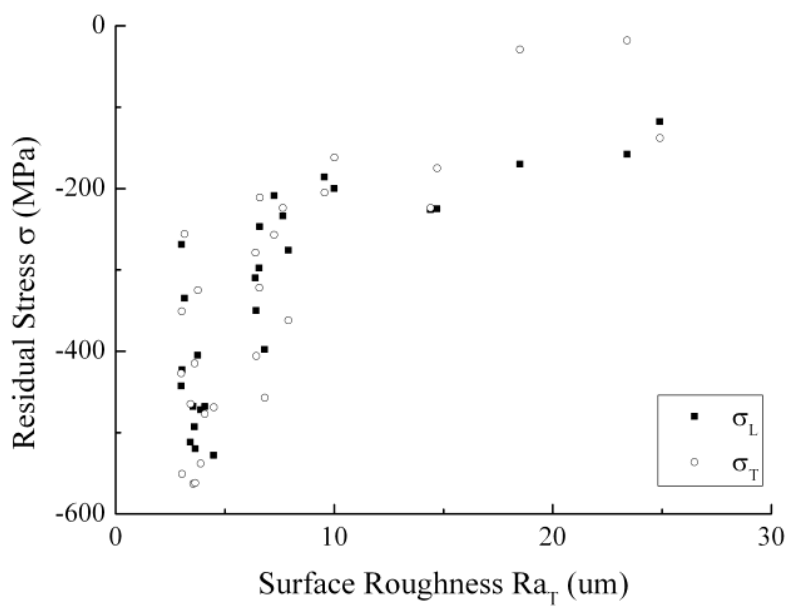

Fig. 12 Correlation between residual stress and surface roughness. 


\section{Conclusions}

The applied study investigated the in-plane surface residual stress resulting from PWJ surface removal process, but did not provide information of the subsurface stress distribution. Thus, it is worthwhile to evaluate the subsurface residual stress distribution.

Thus, PWJ can be used for coating removal and simultaneous development of a compressive residual stress, and/or simultaneous increase of surface roughness (such as surface treatment of medical implants where cementless fixation is required). 


\section{Reference}

Arola, D., Alade, A.E., Weber, W., 2006. Improving fatigue strength of metals using abrasive waterjet peening. Machining Science and Technology 10, 197-218.

Arola, D., McCain, M.L., Kunaporn, S., Ramulu, M., 2001. Waterjet and abrasive waterjet surface treatment of titanium: a comparison of surface texture and residual stress. Wear 249, 943-950.

Arola, D., Ramulu, M., 1997. Material removal in abrasive waterjet machining of metals - A residual stress analysis. Wear 211, 302-310.

Arola, D.D., McCain, M.L., 2000. Abrasive waterjet peening: A new method of surface preparation for metal orthopedic implants. J Biomed Mater Res 53, 536-546.

Brunton, J.H., Rochester, M.C., 1979. Erosion of Solid Surfaces by the Impact of Liquid Drops, Treatise on Materials Science and Technology. C. M. Preece, Academic Press, pp. 185-248.

Buhrke, V.E., Jenkins, R., Smith, D.K., 1998. A practical guide for the preparation of specimens for X-ray fluorescence and X-ray diffraction analysis. John Wiley \& Sons, Inc., New York, USA.

Caydas, U., Hascalik, A., 2008. A study on surface roughness in abrasive waterjet machining process using artificial neural networks and regression analysis method. Journal of Materials Processing Technology 202, 574-582.

Chillman, A., Ramulu, M., Hashish, M., Cantrell, A., 2010. High Pressure Waterjets An Innovative Means of Alpha Case Removal for Superplastically Formed Titanium Alloys. Key Eng Materials 433, 103-111.

Doig, P., Flewitt, P.E.J., 1981. A Theoretical Consideration of the Influence of Surface Profile on the Measurement of Stress Using the X-Ray-Diffraction Method. J Appl Crystallogr 14, 321-325.

Frangini, S., Mignone, A., Dericcardis, F., 1994. Various Aspects of the Air Oxidation Behavior of a Ti6al4v Alloy at Temperatures in the Range 600-700Degrees-C. J Mater Sci 29, 714-720.

Huang, L., Folkes, J., Kinnell, P., Shipway, P.H., 2012. Mechanisms of damage initiation in a titanium alloy subjected to water droplet impact during ultra-high pressure plain waterjet erosion. Journal of Materials Processing Technology 212, 1906-1915.

Meguid, S.A., 1989. Fatigue fracture in the presence of shot-peening residual stresses, Eng Fract Mech. Elsevier Science Publishers LTD, England, pp. 339-359.

Patankar, S.N., Tan, M.J., 2001. Influence of alpha casing on superplastic deformation of Ti-6Al-4V. J Eng Mater-T Asme 123, 144-147.

Soyama, H., 2004. Introduction of compressive residual stress using a cavitating jet in air. J Eng Mater-T Asme 126, 123-128.

Soyama, H., Kusaka, T., Saka, M., 2001. Peening by the use of cavitation impacts for the improvement of fatigue strength. J Mater Sci Lett 20, 1263-1265.

Soyama, H., Odhiambo, D., Mall, S., 2004. Introduction of compressive residual stress into titanium alloy Ti6Al4V by cavitation shotless peening. Journal Society of material science, Japan 53, 836-840. 
Tonshoff, H.K., Kroos, F., Marzenell, C., 1997. High-pressure water peening - a new mechanical surface-strengthening process. Cirp Annals 1997 Manufacturing Technology, Volume 46/1/1997 46, 113-116.

Vosough, M., Liu, P., Svenningsson, I., 2005. Depth profile of titanium alloy (Ti-6Al$4 \mathrm{~V})$ and residual stress measured by using X-ray diffraction after metal cutting assisted high-pressured jet cooling evaluation of etching methods: ION beam (EDOS) and electro-chemical etching. Residual Stresses Vii, Proceedings 490-491, 545-551. 